\title{
India moves to boost its Parsi population
}

I $\mathrm{n}$ a country with 1.2 billion people, India is paying for fertility treatment and counselling aimed at bolstering its diminishing Parsi population.

The number of Parsis has dropped $40 \%$ in 60 years, to 69001 in 2001 (the latest available figures) from 114890 in 1941, according to the UNESCO ParsiZoroastrian Project (Parzor), which aims to preserve the culture and heritage of the Parsi community in India. During this time, the general population in India increased $21 \%$.

Many Parsis are economically important business leaders. They are primarily based in Mumbai, Gujarat, New Delhi and Kolkata, and descended from Zoroastrians in Greater Iran who immigrated in the 8 th or 10 th century to avoid persecution.

A September 2013 report from the Indian Ministry of Minority Affairs, The Central Sector Scheme for Containing Population Decline of Parsis in India, documents underlying factors for the declining Parsi population, including a relatively older age at marriage (27 years for women, 31 for men) and a fertility rate of 0.8 children per woman. In addition, $30 \%$ of Parsis remain single and $31 \%$ are over the age of 60.

Shernaz Cama, a Parsi and director of the Parzor Foundation says many Parsi couples cannot afford fertility treatment. "When only around 200 [Parsi] children are born in Bombay and over 800 Parsis die each year, every child the community can have is very important from the viewpoint of survival," Cama told CMAJ.

Parsis are "extremely Westernized and individualistic," adds Cama. They prefer to live in their own home rather than with their parents like many other Indians. And in the interest of pursuing

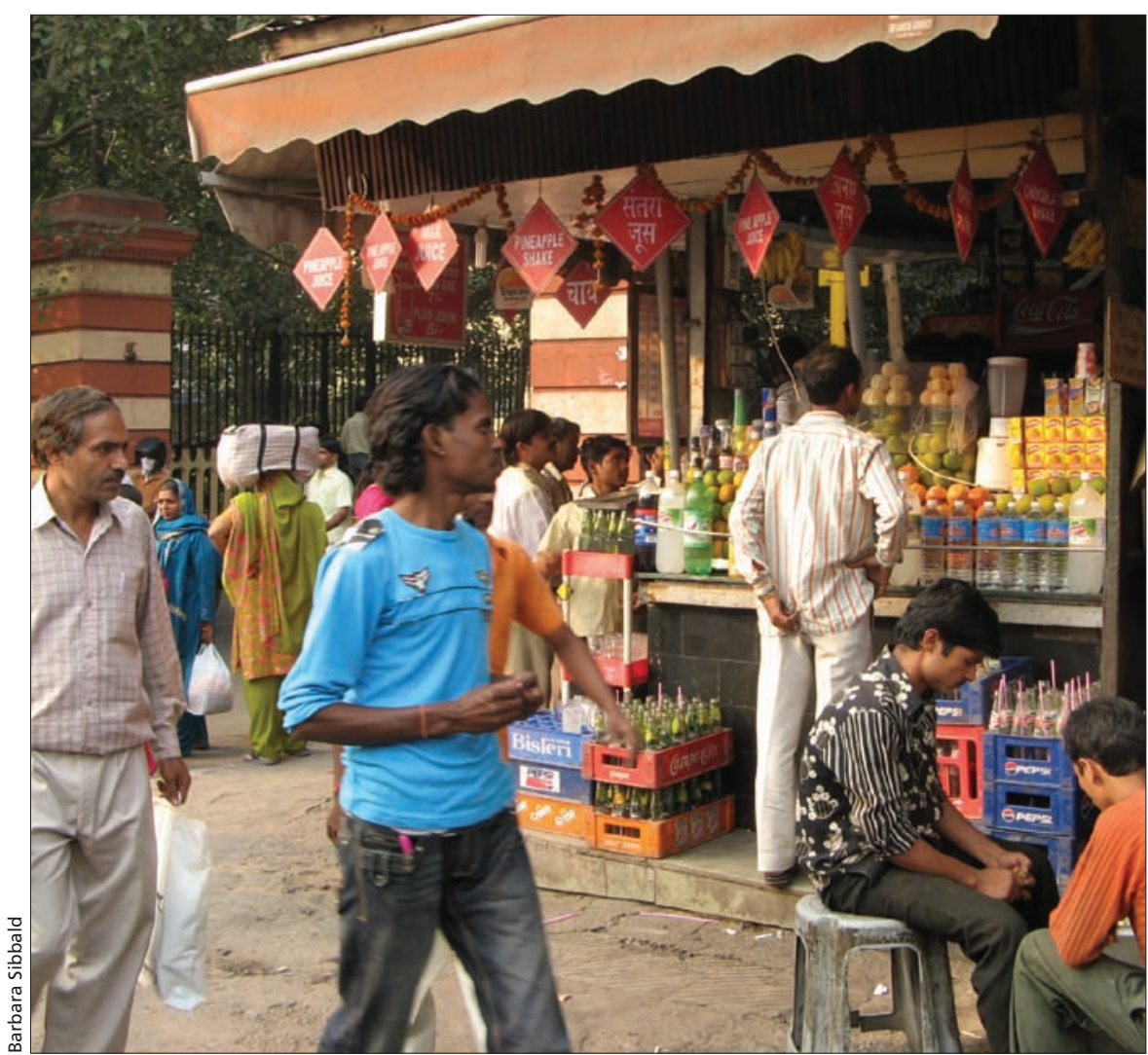

The number of Parsi people in India has dropped $40 \%$ in 60 years. During the same time, the general population in India increased $21 \%$.

their career, they often delay having children, which can affect fertility. In addition, few Parsis have more than one child. "There is no peer or family pressure for more children," says Cama.

Jiyo Parsi (LiveParsi) may well help increase the birth rate and help create positive attitudes to marriage, says Cama. Jiyo Parsi is receiving 100 million Indian rupees ( $\$ 1.8$ million) from the Government of India for programs in four cities. Young people of marriageable age will be counselled to marry early and those who are having difficulties conceiving will be provided with treatment, including in vitro fertilization and intracytoplasmic sperm injection.

Dr. Faram Irani, a Parsi gynecologist and infertility specialist in Mumbai, told CMAJ that the Jiyo Parsi initiative is a "welcome, much needed move that should increase the Parsi population by $10 \%$ by the next decade."

The first fertility centre was set up in mid-February in New Delhi; others will follow in Mumbai, Gujarat and Kolkata. - Sanjeet Bagcchi, MBBS, Kolkata, India

CMAJ 2014. DOI:10.1503/cmaj.109-4757 